Otterbein University

Digital Commons @ Otterbein

Health and Sport Sciences Faculty Scholarship

Health and Sport Sciences

7-2010

\title{
The Ethical Balancing Act of Hospice Care
}

Paul D. Longenecker

Otterbein University

Follow this and additional works at: https://digitalcommons.otterbein.edu/hsports_fac

Part of the Health and Medical Administration Commons

\section{Repository Citation}

Longenecker, Paul D., "The Ethical Balancing Act of Hospice Care" (2010). Health and Sport Sciences Faculty Scholarship. 4.

https://digitalcommons.otterbein.edu/hsports_fac/4

This Article is brought to you for free and open access by the Health and Sport Sciences at Digital Commons @ Otterbein. It has been accepted for inclusion in Health and Sport Sciences Faculty Scholarship by an authorized administrator of Digital Commons @ Otterbein. For more information, please contact digitalcommons07@otterbein.edu. 
The Ethical Balancing Act of Hospice Care

\author{
Paul D. Longenecker, R.N., M.B.A., Ph.D. \\ Assistant Professor, Business and Leadership Studies \\ Lourdes College \\ 6832 Convent Blvd. \\ Sylvania, Ohio 43560 \\ Phone: 419-517-8885 \\ Fax: 419-824-3510 \\ E-mail: plongenecker@lourdes.edu
}




\title{
The Ethical Balancing Act of Hospice Care
}

\begin{abstract}
In providing hospice care, clinicians are confronted with ethical challenges on a daily basis involving their patients and families, their personal values and beliefs and organizational practices. Being able to objectively understand these ethical challenges and having a plan of action to address is essential in effectively fulfilling the role of being a hospice professional.
\end{abstract}


Hospice clinicians are confronted with numerous challenges on a daily basis in the provision of care to their patients. At the heart of many of these challenges are ethical considerations. Many of these issues are triggered by questions such as: Do patient wishes always take precedence over others? How do I deal with family wishes that appear to contradict what the patient told us when able to speak for themselves? What do I do if the patient's behavior demonstrates that he is not interested in receiving hospice care?

The focus of this article is to identify ethical challenges that cause hospice clinicians to question if they are doing the right thing. For the purpose of the article, ethics will be defined as guiding principles that define or govern good conduct. In addition, a framework for evaluation of these dilemmas will be discussed throughout the paper. In looking at the areas that create challenges, six broad categories are defined: ethical versus legal standards, ethical versus operational issues, justice, personal values, truth-telling and professional boundaries. After presentation of a brief case, each of these areas will be explored and addressed specific to the case.

Mary, a nurse for Best Hospice, was heading out to see a new patient, Agnes Smith, that had been admitted to hospice the previous day in her home by Betty, another nurse at Best. Upon arriving, Mary was met in the front yard by a woman, who identified herself as the patient's daughter. Mary recognized the woman as Beth Smith, a former high school classmate. She hadn't pick up on the patient's name, Agnes Smith, when she got the referral since the patient lived on the south side of town and the daughter's name was listed as Elizabeth Jones. Mary knew that Agnes was one of her mother's long time friends and had been her Girl Scout leader. Beth told her she recognized her and had 
hoped that Mary was the nurse visiting since Beth had heard Mary was a hospice nurse. Betty explained to Mary that she had met her outside because she wanted to talk to her away from her mother.

Betty stated that she wanted to make sure Mary had gotten the message that her mother didn't know she was dying and Beth didn't want her told. In fact, she had worked this out with Betty, the nurse that had come yesterday. Mary was to tell her mother that she was a home care nurse. Beth also told Mary she was really glad that Mary was the nurse because she aware of their mothers' close friendship and Beth know she could count on Mary's help after hours with any care issues. Lastly, she said that Mary's visit needed to be short since her mother had a chemotherapy treatment scheduled at the hospital in 45 minutes. Beth, also expressed her appreciation for the hospice paying for her mother's chemotherapy treatments since they cost \$3,000 per treatment. Mary was overwhelmed by all this information since she was unaware of any of these details.

\section{Ethical versus Legal Standards}

Often in the evaluation of dilemmas that arises around end-of-life care, the argument that is used to support actions to be undertaken is a legal one. We must either do something or avoid doing something because the law says so. A common area where this arises is the issue of patient abandonment. "We must continue care or we will be abandoning the patient" is the cry for action. The fear of legal action frequently drives this response (Kyba, 2002). In looking at the issue from an ethical perspective, we must ask questions like "what are the patient desires?", "are we adding value to the patient's plan of care?", "does the patient want our services?" and "are 
the patient wishes in sync with what we can offer?". These questions address principles of patient autonomy, are we doing good and not causing harm, respecting the patients' rights but also respecting the rights of the hospice provider and their team of clinicians (Cameron, 2003; Kyba, 2002; Lorenson, Davis, Konishi \& Bunch, 2003). This ethical concept of patient autonomy will be also discussed in the justice section. This difference between legal and ethical has been described as the legal standard being the floor of the room and the ethical standard the ceiling of the room. In other words, the legal standard is the bare minimum of what should be done and the point at which the conversation begins - - not ends. In taking an ethical position, clinicians need to dig below the surface of the situation and attempt to address the problem, not only the symptoms. Questions to be asked in this case include: Are we meeting the needs of the patients and their family? Are the concerns of the clinicians being addressed to assist them in their ability to meet patient needs? Does the hospice provider have the ability to address the unique needs of this patient? Only then can the higher standard of ethical practices be addressed and met.

In looking at this challenge related to the case, Mary is immediately confronted with several issues. One, are the stipulations stated by the daughter in the best interest of the patient and the hospice? Can the hospice discharge or transfer the patient if hospice policies require that the patient be told staff is from hospice and the family refuses? What if the economic burden of paying for chemotherapy will financially interfere in the care of other hospice patients or threaten the livelihood of the organization? It would appear that Mary needs to address these issues with the hospice's leadership and develop a plan on how the issues will be handled. Some of these questions relate to the next section. 


\section{Ethical versus Operational Issues}

Dilemmas that arise are often fueled by emotions and can be complicated by the many different parties involved. A key challenge that arises in resolving a dilemma is "if a dilemma is an ethical one or not". A dilemma "is ethical rather than practical if one could reasonably appeal to moral reasons for taking two opposing courses of action" (Keenan, n.d., p. 1). In other words, is it more than an emotional situation that has triggered a need to define a resolution? A good example of this would be employee theft, which is also an organizational issue. If one employee knows that another employee has stolen from a patient, employee policies are usually pretty clear that the employee should be reported to management. Even if the reporting employee is the other employee's best friend, there is a clearly defined action to be taken. While it may be an emotional dilemma for the reporting employee, it is not an ethical dilemma. Often, dilemmas arise that have been previously resolved and operationalized however may still be perceived as being ethical in nature. Hospice clinicians need to be aware of this distinction and be able to differentiate between ethical and operational dilemmas. This can be achieved by ongoing ethics training. To facilitate awareness, the training should consist of a review of organizational ethics policies, a case presentation with group analysis and an understanding of the operations of the organization's ethics committee (Gastmans, 2002; Kyba, 2002).

In looking at this case, it would appear to be fairly straight forward whether the issues are ethical or operational. Does the hospice have a policy on informing patients that define that staff are from hospice? Do they have a policy regarding professional boundaries pertaining to the afterhour's request? Do they have policies related to patients receiving chemotherapy? If yes to all three, it would appear that no ethical dilemmas exist. All these issues have been addressed 
through the hospice's policies. Mary may need to clarify the policies for Mrs. Smith's daughter. If the answer is no, Mary is confronted with situations that have no defined precedence and would need to seek outside input in resolving this dilemma.

\section{Justice}

The concept of justice is frequently one of the most challenging ethical principles to integrate and implement into health care settings. Justice is defined as "an ethical principle stating the duty to treat all fairly, distributing the risks and benefits equally" (NHPCO, 2006, p. 36). This definition is normally attached to the concept of distributive justice. Another form of justice is commutative justice that refers to the special relationship that occurs when a mutual bond is created. The admission of a patient to hospice would represent the establishment of this type of bond. Because of this, a hospice is now held to a higher standard of practice. To explore the relationship further, one additional perspective of justice needs to be explored that incorporates the other concepts. This concept is the idea of "justice for all". Although, not defined in the literature, "justice for all" broadens the definition of justice to include all parties involved.

When a patient consents to receiving hospice care, the patient is provided with a list of their rights helping to explain how they will be treated in a "fair and equitable manner" (CMS, 2008). The patient and their family will also be provided with a list of their responsibilities in this mutual relationship. In other words, how they will treat the hospice provider and their clinicians in a "fair and equitable way". These responsibilities normally involve keeping the hospice provider informed of changes, identifying concerns with care and notifying the provider of an inability to comply with the plan of care. Although, the burden on the hospice would be at a 
higher level, it does not discount the expectations that hospice clinicians should have that they will be treated fairly by the patient and the family. Two examples are:

1. If the patient or family does not wish to comply with the agreed - upon plan of care, hospice clinicians are not required to be part of that plan. This involves not following a plan of care that was agreed upon by both sides, based on routine standards of hospice practice. In this scenario, it is appropriate to discharge a patient, if after a thorough review of the situation, it is identified the patient actions and the plan of care are not compatible or congruent.

2. The patient can request whatever services and procedures that they desire, but if the provision of the services would interfere with the ability of the hospice provider to care for other patients or threaten its livelihood, they have an obligation to inform the patient. They should then help the patient find a provider that can fulfill their request. In this example, the provision of chemotherapy treatment, in the case being discussed may represent such a service.

A key challenge that frequently inhibits this process is the inherent paternalistic nature of health care clinicians (Gastmans, 2002). Individuals involved in health care are attracted to the field because they like to help others. Issues arise when individuals do not want hospice help. Although, the individual could benefit from hospice care, not everyone desires hospice care. In this broader definition of justice, all parties involved are treated fairly.

The case identifies several concerns with justice. One, if the patient is competent, she would need to be informed of her rights and responsibilities as a hospice patient. Two, in exploring the situation from each party's perspective, the issue of chemotherapy would 
need to be clarified to ensure that mutual agreement on the plan of care has been reached. In this case, the daughter seems to be defining the parameters of care, without first consulting the others parties involved (i.e., hospice, her mother, policies, etc.).

\section{Values}

Values are a very important part of the ethical balancing act (Taylor \& Carr, 2009; Cameron, 2003; Lorensen et al, 2003, Kyba, 2002). Everyone has values that define who they are and what they believe in that allows them to judge what is right and wrong (Center for Ethical Leadership, n.d.). These values can fit into two broad categories: instrumental and terminal values. Terminal values are desired end-states; happiness, family security, salvation; while instrumental values are how you achieve the terminal values; being responsible, being honest, being ambitious (Rokeach, 1973).

The ability of hospice clinicians to provide end-of-life care includes the need to understand what core values drive who they are. In addition to knowing what these values are, knowing why they are important to them is essential (Taylor \& Carr, 2009). Conflict arise within clinicians if when they encounter a situation that creates a feeling of internal turmoil, they are unsure why. This feeling of turmoil may be triggered by the values involved in the situation. Unknown to their conscience mind is the underlying trigger for the conflict. By exploring the values important to them, clinicians can be better prepared to proactively meet and address value laden situations.

While a lack of awareness of core values may trigger conflict, values inherently held by most people do not vary significantly (Allicock et al, 2008; Frederick \& Weber, 1990; Longenecker, 
2009). This finding would appear to demonstrate that identifying common ground around values is fairly simple. An awareness of values that are important is essential to understanding this commonality.

In the case, the emotions attached to the values of family, friendship and loyalty could be key triggers for Mary. Her prior relations with Agnes and Beth and her mother's friendship with Agnes may create a value conflict for her. Professional expectations competing against perceived personal obligations may cloud her perspective. Mary needs to be able to acknowledge the conflict, make others aware of it and resolve it so patient care is not compromised.

\section{Truth-Telling}

The importance of telling the truth is a concept that we are taught at a young age. The connotation of harm that can be caused by lying is illustrated by the growth of Pinocchio's nose that many heard as a child (Hillert, 2006). As identified by hospice professionals, truth-telling is one of the most challenging ethical principles to deal with (Longenecker, 2006; Lorenson et al., 2003).

The conflict associated with truth-telling (veracity) appears to be its apparent connection to the ethical principle of not doing harm (nonmaleficence). As we learned from the Pinocchio example, telling a lie can cause harm. But what happens when we tell the truth and it causes harm? There are certainly simplistic examples of this such as when someone is asked if you like someone else's new outfit or hairstyle. Will telling the truth or lying cause more harm? There 
probably is not a right or wrong answer to this individual scenario. It is situational and relational based. But what if the situation is to "not to tell Mom she is dying". This is a situation that hospice clinicians can relate to based on being faced with being asked to not wear their hospice name tag. And to add to the scenario, the patient has asked you not to tell their family that they know "they are dying". This is a case of being "stuck between a rock and hard place".

In resolving this dilemma, the best advice the writer has heard came from a community member of an ethic committee. He said "why can't you tell them that lying is not an option, so what should we do if asked?" The point from this observation was this is not a situation to be addressed in isolation. As with most ethical dilemmas, truth-telling is not only an individual issue but also an organizational standard involving justice. How do we treat everyone fairly? In addressing commonly occurring situations, organizational standards are defined ensuring consistent responses. How is the question of not wearing a hospice name badge addressed? What do we tell families when they ask not to tell the patient they are dying or the patient asks not to tell the family that they know? How do we handle requests if they involve specific cultural beliefs? When these situations are operationalized, the ethical nature of the issue is often minimized. Consistency of practice among hospice clinicians is the strongest example of ethical practice that can be displayed. If truth-telling means the same thing to all members of the hospice team, the chances of dilemmas arising can be reduced.

The issue of truth-telling would appear to be at heart of this case. Without resolution of this issue, the other issues become irrelevant. The question would appear to be "does Mary's hospice have a policy on not telling them that the staff are from hospice?" Based 
on the initial admission nurse's reported response to this question, it would appear that they don't or it wasn't followed. Addressing the issue at this point will facilitate the overall plan throughout the duration of care.

\section{Professional Boundaries}

Similar to truth-telling, dealing with professional boundary issues is one of the most common challenges for hospice organizations (Longenecker, 2006). The inherent nature of hospice care creates an environment where the boundary between personal and professional relations can be blurred. The dying process is an intimate setting where the emotions of all parties involved are close to the surface. The ability to develop close relationships with patients and their families is a possibility for hospice clinicians. The vulnerability of the setting, often a patient's home, is "ripe" for ethical dilemmas to arise. The need to get close to the patient and their families is essential to providing quality end-of-life care, but where is the line between close and too close?

Personal values can be a trigger for testing the ethical boundary of professional practice. The patient/family relationship may trigger something in a hospice clinician's belief system, based on past experience, which may cause that professional boundary line to be crossed. In understanding and exploring the personal values of hospice clinicians, they should be aware of these trigger points and identify how to best address the situation. This may include asking to be removed from the case if they do not think that they can effectively deal with it. From an operational perspective, two key strategies can be implemented to help minimize professional boundary violations. One, "establish policies and procedures based on sound standards and past experiences and hold staff accountable to them, and two, educate staff on these situations and 
be open to input from patients, families and other community and health providers" (Longenecker, 2006, p. 37).

The professional boundary challenge of the case presented appears to be the daughter's inference that Mary would be available after-hours, based on their past personal relationship. Mary would seem to have two options. One, to be involved in the professional care of the patient and define her inability to assist afterhours related to professional standards and two, inform her supervisor of the personal relationship and asked to not be involved in Mrs. Smith's care. Although, in taking a position it may still trigger boundary issues, letting others know that you're aware of the issue should help in minimizing the risks to all involved

\section{Conclusion}

Numerous ethical challenges confront hospice clinicians on a frequent if not daily basis requiring awareness and being well versed in how to handle these situations. As it appears to the writer, based on serving on ethics committees of health care organizations in the U.S. for the last 25 years, end-of-life care dilemmas are at the forefront of ethical practice (Pozgar, 2005). Besides the challenges identified within the article, numerous other potential ethical dilemmas include artificial nutrition and hydration, palliative sedation, futile care and hospice business practices. For hospice clinicians to remain aware and informed; being proactive in maintaining ethical practice standards through self-awareness of their beliefs, understanding the ethical challenges confronting their organization and being an active part of the process will help address the dilemmas. Mary's awareness of the delicate ethical balancing act of being a hospice clinician 
will help her meet, identify and effectively address the challenging dilemmas, ethical or not, that she faces. 


\section{References}

Allicock, M.; Sandelowski, M.; DeVellis, B. \& Campbell, M. (2008). Variations in meanings of the personal core value "Health". Patient Education and Counseling, 73, 347-353.

Center for Ethical Leadership (n.d.). Core Values Assessment Tool. Seattle, Washington. Retrieved from http://www.ethicalleadership.org .

Center for Medicare and Medicaid Services (CMS) (June 8, 2008). Medicare and Medicaid Programs Hospice Conditions of Participation: Final Rules. Federal Register, 73(109), 32087-3220

Cameron, M.E. (2003). Our best ethical and spiritual values. Journal of Professional Nursing, 19(3), 117-118.

Frederick, W.C. and Weber, J. (1990). The values of corporate managers and their critics: an empirical description and normative implications. In W.C. Frederick \& J. Weber (Eds.). Business Ethics: Research Issues and Empirical Studies, (pp.123-144). Greenwich, CT:

\section{JAI Press.}

Gastmans, C. (2002). A fundamental ethical approach to nursing: Some proposals for ethics education. Nursing ethics, 9(5), 494-507.

Hillart, M. (2006). Pinocchio. Chicago, IL: Norwood House Press.

Keenan, M. (n.a.). Ethical Principles, Rights and Approaches to Ethics. Ethics for Hospice Managers Module: Management Development Program (MDP). Alexandria, VA: NHPCO.

Kyba, F.E. (2002). Legal and ethical issues in end-of-life care. Critical Care Nursing Clinics of North America, 14, 141-155. 
Longenecker, P. (2009, October). Core values of hospice professionals: What are they telling us? Research paper presented at Ohio Hospice \& Palliative Care Organization Webinar.

Longenecker, P. (2006). What challenges face hospice managers? Insight, Fall 2006, 36-37.

Lorenson, M., Davis, A.J., Konishi, E. \& Bunch, E.H. (2003). Ethical issues after the disclosure of a terminal illness: Danish and Norwegian hospice nurses' reflections. Nursing Ethics, 10(2), 175-185.

National Hospice and Palliative Care Organization (NHPCO) (2006). Ethical Principles: Guidelines for Hospice and palliative Care. Clinical and Organizational Conduct. Alexandria, VA: NHPCO.

Pozgar, G.D. (2005). Legal and Ethical issues for Health Professionals. Sudbury, MA: Jones and Bartlett Publishers

Rokeach, M. (1973). The Nature of Human Values. New York, N.Y.: The Free Press.

Taylor, E.J. \& Carr, M.F. (2009). Nursing ethics in the Seventh - day Adventist religious tradition. Nursing Ethics, 16(6). 707-718. 
Definitions of Ethical Concepts (Pozgar, 2005)

Autonomy: Right of an individual to make his or her own independent decisions (p. 353).

Beneficence: Describes the principle of doing good, demonstrating kindness, and helping others (p.353).

Ethical Dilemma: A situation that forces us to make a decision that involves breaking some ethical norms or contradicting some ethical value. The effect of an action may put others at risk, harm others, or violate another person's rights (p. 356)

Futility: Having no useful results. Futility of treatment, as it relates to medical care, occurs when the physician recognizes that the effect of treatment will be of no benefit to the patient. Morally, the physician has a duty to inform the patient when there is little likelihood of success (p.356).

Justice: The obligation to be fair in the distribution of benefits and risks (p. 358).

Nonmaleficence: The duty to avoid causing harm to patients (p. 17).

Resources

Center for Practical Bioethics $\quad$ www.practicalbioethics.org

The Hastings Center $\quad$ www.thehastingscenter.org

Jennings, B., Ryndes, T., D’Onofrio, C. \& Baily, M.A. (2003). Access to hospice care:

Expanding boundaries, Overcoming barriers. The Hasting Center Report, Special Supplement, March-April. 